\title{
Exploring the Online Behavior of Users of Online Depression-Focused Communities: Comparing Communities with Different Management Types
}

\section{Jingyun Tang \\ Xiaoxu Yao \\ Guang Yu}

School of Management, Harbin Institute of Technology, Harbin, I5000I, People's Republic of China
Correspondence: Guang Yu

92 Xidazhi Street, Nangang District,

Harbin, Heilongjiang Province, People's

Republic of China

Tel +86-139-3649-0774

Email yug@hit.edu.cn
Introduction: Online depression-focused communities (ODCs) are popular avenues that help people cope with depression. However, to the best of our knowledge, research on online behavior and differences among users from managed and unmanaged ODCs has not been explored.

Methods: We collected data from the most popular managed depression-focused community (MDC) and unmanaged depression-focused community (UDC) in China. Text classifiers were built using deep-learning methods to identify social support (ie, informational and emotional support) and companionship expressed in the posts of these communities. Based on the content of their posts, community users were clustered into supporters and ordinary members. Econometrics was used to analyze the factors that influence supporters' contributions and ordinary members' participation in MDCs and UDCs.

Results: Community response has a positive impact on supporters' social support and time span in the UDC, but this impact is not significant in the MDC. Supporters expressing positive emotions provide more social support, and they are more willing to serve in the MDC. Supporters expressing negative emotions tend to have longer engagement with the UDC. In addition, community response has a positive effect on ordinary members' participation in both communities, and this effect is greater in the UDC. Ordinary members expressing positive emotions are more active in the MDC, and ordinary members expressing negative emotions are more active in the UDC.

Conclusion: This study improves the understanding of users' online behaviors in ODCs, provides decision-making support for designers and managers of ODCs, and provides information that can be used to help improve aid for people with depression provided by community and mental health professionals.

Keywords: managed depression community, unmanaged depression community, supporters' contribution, members' participation, text-mining, econometrics

\section{Introduction}

The prevalence of depression has been consistently increasing in recent years, and the World Health Organization now ranks depression as one of the most burdensome diseases in the world. ${ }^{1}$ Medical professionals generally represent an important source of information for people with health problems. However, many people with depression are reluctant to seek professional help. ${ }^{2}$ In other words, the stigma associated with depression represents a prominent barrier to seeking information regarding addressing the condition. ${ }^{3,4}$ 
Online social media allows users to access information and interact with others anonymously, which is particularly important for people with stigmatizing diseases. ${ }^{4}$ People with depression are reluctant to communicate with others in real life, but are willing to communicate with people online who have had or are currently experiencing the same problems. ${ }^{5,6}$ Online communities provide a platform for people with depression to express themselves and communicate with others, which can help them establish social relationships, reduce their sense of isolation, and increase their ability to address their illness. ${ }^{7}$

Previous studies on depression generally used offline or online surveys to investigate the prevalence of depression, the characteristics of depressed users, and the risk factors for depression. ${ }^{8-10}$ The emergence of ODCs provides a new data source for research on depression. Some studies have used text analysis such as natural language processing to analyze the content of posts in ODCs and have found discussion of depression-related issues as the most common theme. ${ }^{11-13}$ Additionally, some researchers have explored the characteristics of ODC users, including demographic, ${ }^{7,10}$ expression, ${ }^{14}$ and emotional characteristics. ${ }^{15}$ Frequent expression of negative emotions was found to be the most prominent feature of community users. ${ }^{15}$ Most studies believe that community participation has a positive impact on users, mainly because participation in an ODC reduces social isolation of people with depression; ${ }^{16}$ provides opportunities to seek more health information, suggestions, and opinions from others; ${ }^{17-19}$ and serves as a platform for online interventions. ${ }^{20,21}$ However, considering that problematic Internet use is a risk factor for depression, ${ }^{22-24}$ it is uncertain whether participation in ODCs is conducive to the improvement of depressive symptoms. In addition, some studies have questioned the positive impact of ODC in terms of online intervention implementation. The loss of participants and the low activity of community users is a significant problem hindering the implementation of online interventions. ${ }^{25}$

The most important aspect of an online community is the supply of information, ${ }^{26}$ which largely depends on active communication among users. ${ }^{27}$ Thus, active participation is essential for the sustainability of online communities. ${ }^{28}$ Recognition of these problems has prompted many researchers and managers of online communities to attempt to identify the factors that motivate users to engage in continuous participation in such communities.
Previous research of users' participation in online communities has examined both intrinsic and extrinsic motivations. Through these studies, personal characteristics, self-efficacy, altruism, empathy, and needs have been found to be the intrinsic motivations that most affect the behaviors of users of online communities. In terms of personal characteristics, users with higher extraversion $^{29-32}$ and conscientiousness ${ }^{31,33}$ have been found to be more active in online communities, whereas those with higher neuroticism have been found to be less active in online communities. Gender is another factor that influences users' online behavior. Compared to men, women tend to ask fewer questions online, but seek friendship more actively. ${ }^{33}$ Self-efficacy, altruism, and empathy positively influence one's desire and confidence to contribute to online communities ${ }^{34-37}$ and encourage users to participate more actively in discussions. Finally, regarding needs, users may engage with online communities in order to satisfy social needs, self-expression needs, and information needs. ${ }^{38-40}$

Meanwhile, the extrinsic motivations that have been found to influence online community behavior include group identity, perceived similarity, reciprocity, community quality, and social support. Regarding group identity, several studies have shown that communities with strong group identities usually have more members to actively participate in them; ${ }^{41,42}$ this may be because people with a common identity tend to have similar goals, rules, and interests, and are, therefore, more likely to share information with each other and participate in discussions. ${ }^{43}$ Next, perceived similarity, which has been especially examined in terms of online health-focused communities, ${ }^{44}$ relates to users viewing other users as experiencing situations similar to the ones they themselves experienced; this perception causes the other users to be perceived as more attractive, trusted, and understood than dissimilar individuals. ${ }^{45}$ In relation to health problems, the collective experience and information of the many people who comprise online health communities is often perceived as more credible than the information given by health-care providers ${ }^{46}$ this consequently increases participation in such communities. The next external motivation for online community behavior is reciprocity. Perceived reciprocity positively influences members' satisfaction and intention to participate in community activities. ${ }^{47}$ In particular, response speed, value, and frequency are key reciprocityrelated factors of online communities, as these factors directly influence the quality of dialogue. ${ }^{48}$ Next, 
community quality has a significant influence on how users perceive the community and, therefore, influences their online behavior. When members are satisfied with the quality of a community (ie, they think the community is safe, convenient, and reliable, and that their privacy is protected) they participate willingly. ${ }^{49}$ In contrast, when users feel that the quality of messages is poor, the interaction design is bad, and/or that their private information may be exposed to others in the community, users are reluctant to participate. ${ }^{50}$ As health-information disclosure may incur privacy risks, privacy concerns have a particularly strong influence on individuals' willingness to communicate personal health information in health- and mental health-focused communities. ${ }^{51}$ Finally, users who obtain social support from online health-focused communities have been found to be more likely to maintain longterm relationships with these communities. ${ }^{52}$

Few studies have specifically investigated participation in ODCs. One study by Sadeque et al noted a problem regarding the reduction in the number of users in ODCs. ${ }^{53}$ They developed a model to predict when the members would quit by analyzing changes in language use and activity level. ${ }^{53}$ Another study by Lu et al explored factors driving patients' information sharing in ODCs from the perspective of social capital and found that social interaction ties and the sense of shared identity and trust positively affect information sharing between patients with depression. ${ }^{54}$ However, these studies and previous studies on users' participation in online health communities tend to focus on a single community without considering differences in community types, which are critical in understanding users' online behavior.

In China, while on one hand the prevalence of depression is increasing annually, on the other, the scarcity and imbalance of mental health services, results in a low rate of diagnosis and treatment of depression. ${ }^{55,56}$ Consequently, ODCs provide a good platform for understanding and helping people with depression. There are many ODCs in China. However, some communities cannot fulfill their goals or are even forced to suspend operations because of the small number of active participants. ${ }^{54}$ Therefore, it is very important to understand the relationship between different community types and members' participation.

China-based ODCs can be divided based on their operation style and management type into managed depression-focused communities (MDCs) and unmanaged depression-focused communities (UDCs). ${ }^{15}$ MDCs have community managers and professional support groups, and they disclose health information regarding depression and provide professional help to community members. However, such communities often have constraints such as a need for users to authenticate their identity, and restrictions on freedom of speech. UDCs are communities formed by people with depression; they do not feature professional support groups, and there are no restrictions on speech. In general, well-managed communities attract a high number of participants. However, in recent years, UDCs have tended to outperform almost all MDCs with regard to the number of participants and posts in China. ${ }^{15}$ This discrepancy is worth noting.

In addition, communities tend to feature both supporters (ie, users who provide support to others) and ordinary members. The supporters' contribution and the ordinary members' active participation are considered necessary for the survival of the community. ${ }^{28,36}$ However, these two participant types have different motivations underlying their participation. Thus, we attempted to bridge these gaps by addressing the following two research questions:

RQ1: How does motivation affect supporters' contribution and ordinary members' participation in ODCs?

RQ2: How do the effects of motivation on supporters' contribution and ordinary members' participation differ between MDC and UDC?

\section{Methods}

\section{Data Collection and Preprocessing}

In this study, the depression-focused community on Baidu Tieba was chosen as the MDC. Baidu Tieba is the largest Chinese online community in the world, and its depression-focused community is one of the most popular depression-focused public communities. To date, the community has accumulated over 10 million posts and has over 100,000 participants. Meanwhile, a comment thread on Sina Weibo was chosen as the UDC to examine. Sina Weibo is similar to Twitter, and is one of the most popular social media platforms in China. In 2012, a Sina Weibo user, "zoufan," died by suicide related to depression and posted a farewell post on the thread. Over one million comments have been posted in response to this farewell post, and the number continues to grow (the exact number is unknown as, when a post receives over 100 comments, the total number of comments is no longer shown). To our knowledge, this represents the largest and most representative UDC. ${ }^{15}$ In addition, the similar 


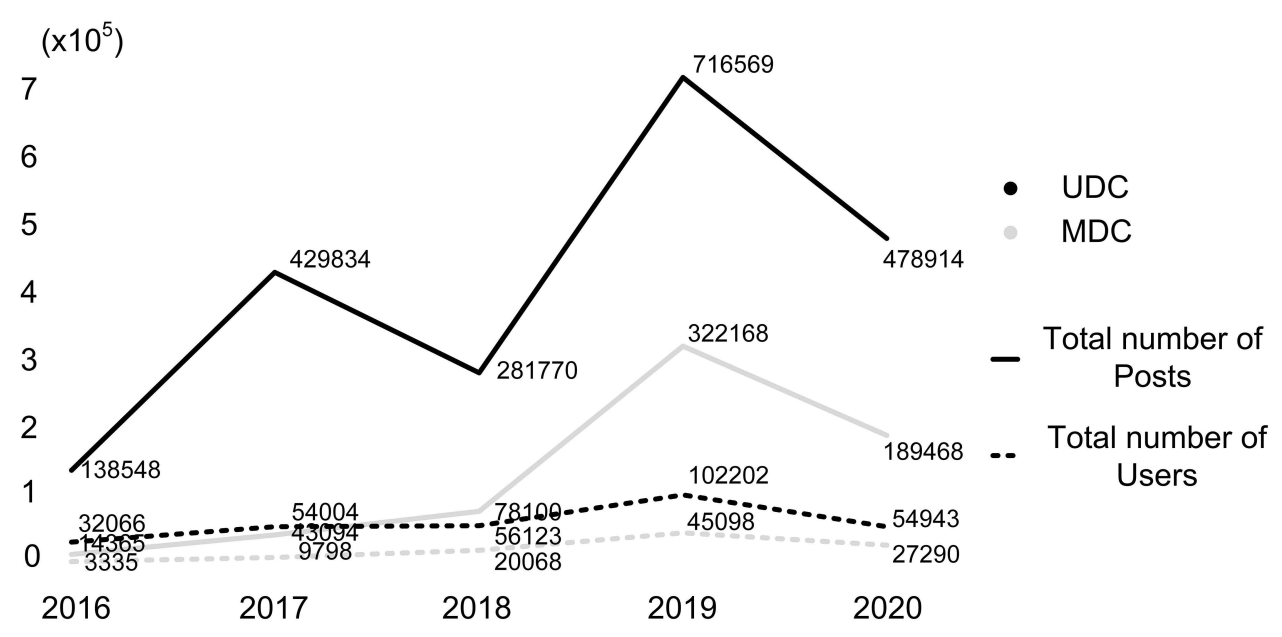

Figure 1

participation patterns of these communities are another reason we chose to examine them in our research. We used Python to write a crawler program and collect all posts (comprising original posts and interactions) from the two communities for the period of January 2016 to November 2020. For each post, we collected the content of the post, the username of the poster, and the date of the post. We then preprocessed the data by removing symbols, geographic locations, and web addresses, and retained only the text information. No posts were removed from the data during the preprocessing steps. Figure 1 shows the number of posts and users for the MDC and UDC across the study period. There is a spike in posts in both the UDC and the MDC in 2019, which may result from a survey and data report on depression in China. ${ }^{57}$ The report, from an influential institute, mentions the depression communities in Sina Weibo and Baidu Tieba, drawing attention to and raising the profile of both communities.

No ethical review was required for this research because publicly available data were used in this study, ${ }^{58}$ however, to protect user privacy, we removed users' identity-related information from the dataset.

\section{Roles of Community Users}

There is no obvious role division in online depression communities; therefore, to distinguish the roles of community users, we divided the users into supporters and ordinary members based on the content of their posts. This dataprocessing process mainly comprised two sections, one focused on text classification and the other on user clustering. The details are presented in the following sections.

\section{Taxonomy of Social Support}

It was necessary to build a text classifier to classify each post in each community. Posts were divided into two categories: social support and companionship. Based on social support theory, the main types of social support commonly provided in online health-focused communities are emotional and informational support. ${ }^{59,60}$ Therefore, we developed the coding scheme presented in Table 1.

Considering the differences between the MDC and UDC regarding the language styles users apply, separate coding processes and classifier training were used for the two communities. The post-coding processes for the communities' posts were as follows: Two research members coded 10,000 posts from each community using the coding scheme. When disagreements arose between the two research members regarding the coding of a post, they held discussions until an agreement was reached. Finally, to compute the inter-rater reliability, a third research member who was experienced in the field of mental health

Table I Coding Scheme

\begin{tabular}{|l|l|}
\hline Support Type & Description \\
\hline Social support & $\begin{array}{l}\text { Delivering informational support, including } \\
\text { information, advice, teaching, personal experience, } \\
\text { guidance, or referral regarding depression; } \\
\text { Providing emotional support, including } \\
\text { understanding, empathy, care, comfort, } \\
\text { encouragement, sympathy, or recognition. }\end{array}$ \\
\hline Companionship & $\begin{array}{l}\text { Posts that do not provide social support, such as } \\
\text { chatting, greetings, revealing personal information } \\
\text { about oneself }\end{array}$ \\
\hline
\end{tabular}


Table 2 The Text Classifiers' Accuracy and FI Scores for Social Support and Emotion

\begin{tabular}{|l|l|l|l|}
\hline Classification & Community & Accuracy & FI Scores \\
\hline Social support & UDC & 0.9487 & 0.9077 \\
& MDC & 0.9546 & 0.9076 \\
\hline \multirow{2}{*}{ Emotion } & UDC & 0.8428 & 0.8354 \\
& MDC & 0.8492 & 0.8239 \\
\hline
\end{tabular}

Abbreviations: UDC, unmanaged depression-focused community; MDC, managed depression-focused community.

coded a random sample of 1000 posts from the MDC and 1000 from the UDC. All kappa values were $>0.85$.

Next, the labeled datasets were used to train text classifiers. This was performed using the pre-training language model Bidirectional Encoder Representations from Transformers, which was developed by Google in 2018 and features new state-of-the-art results for many language-classification tasks. ${ }^{61,62}$ Classifier performance was evaluated based on accuracy and F1 scores. ${ }^{63}$ The results for the classifiers are presented in Table 2.

\section{User Clustering}

After identifying the post types according to social support, we aimed to build profiles for each user from the two communities by aggregating their posts by type. A $1 \times 2$ vector was used to represent each user's post type. The elements in the vector represented the proportion of posts relating to social support and companionship. For example, if a user published 10 posts, with two featuring social support and the remaining eight featuring companionship, the user's vector would be $<0.2,0.8>$.

Next, we applied the classic k-means clustering algorithm to cluster the user profiles of each of the two communities. The optimal number of clusters from the k-means clustering results was estimated using the R package NbClust. ${ }^{64}$

\section{Motivations Underlying Users' Online Community Behavior}

After determining, through clustering, the roles users performed in the communities, we explored their online behaviors in these communities. Specifically, this concerned the contributions made by the supporters and the participation of the ordinary members.

First, the motivations underlying supporters' contributions and ordinary members' participation were analyzed. Through this, variables associated with motivation were extracted. Then, a regression model was applied to perform estimations.

\section{Motivation Analysis}

(1) Intrinsic motivation

Emotion is an internal motivation that affects supporters' contributions to online communities. In ODCs, supporters with more positive emotions may be more willing to provide emotional support to community members and encourage them to actively address their illness. In addition, supporters want to improve their status in the community and earn the respect of others via knowledge-sharing, which motivates them to contribute more information support. ${ }^{65}$

Negative emotion is a common characteristic of people with depression, ${ }^{59,66}$ and those who frequently express negative emotions tend to show higher levels of depressive symptoms. ${ }^{67-69}$ The stigma of illness hinders social activity in real life. The anonymity of online communities allows people with depression and negative emotions to express their emotions and disclose their illness without embarrassment; thus, such communities allow them to express themselves more actively and interact with others. Therefore, emotion is an internal motivation that affects ordinary members' participation in ODCs.

(2) Extrinsic motivation

To promote the development of online doctor-patient communities, several measures are used to ensure doctors' and patients' continuous participation; such measures include improving incentive mechanisms, optimizing the service delivery process, and adjusting the prices of premium doctor-patient interactions. ${ }^{70}$ In contrast, in ODCs, there is no financial exchange among users; thus, extrinsic motivations such as monetary rewards may not be the main drivers of supporters' contributions to these communities. ${ }^{71}$ Individuals contribute to the community and expect their efforts to be recognized. Community recognition can encourage them to make ongoing contributions. ${ }^{27,72-74}$ Community response (questions received from other members or responses to comments) can reflect other members' recognition of certain contributions, whether these responses are positive or negative. For example, posts reflecting negative emotions, it can be regarded as seeking help and make supporters feel needed by the community. Therefore, getting more responses will encourage supporters to increase the frequency of their support. 
Previous studies have shown that social support can increase community members' participation in online communities. ${ }^{52}$ Interactions that do not feature social support, such as general chatting and discussions of one's illness, can help people establish contact with others who have a similar health status; this can contribute to reducing people's sense of social isolation. Thus, an interaction that does not feature social support can also motivate members to post and interact on online community portals. Therefore, community response is an extrinsic motivation that affects ordinary members' participation in ODCs.

\section{Operationalization of Variables Influencing the Support Group's Contributions}

(1) Independent variables

The independent variables were community response (Res) and emotion (Emo). Community response was defined as the total number of responses received by the supporters.

Measurement of emotion was divided into two parts: emotion classification and calculation. First, to identify the emotions in each post, we used the same method as the one described in Section 2.2.1 regarding the building of the text classifier. Posts could be divided into three categories in terms of emotion: positive, negative, and neutral. The performance of the classifier with regard to classifying emotion is included in Table 2. After determining the category of each post, we calculated the emotion values. The calculation rule was the total number of positive-emotion posts minus the total number of negative-emotion posts, divided by the total number of posts; the equation is as follows:

$$
E V_{i}=\left(T_{p o s}-T_{\text {neg }}\right) / T_{i}
$$

Here, $E V_{i}$ represents the emotion value of user i, $T_{p o s}$ represents the total number of positive-emotion posts from user $\mathrm{i}, T_{\text {neg }}$ represents the total number of negativeemotion posts from user $\mathrm{i}$, and $T_{i}$ represents the total number of posts from user i. The closer $E V_{i}$ is to 1, the more positive the user's emotion; the closer the value is to -1 , the more negative the user's emotion.

\section{(2) Dependent variables}

The dependent variables were the supporters' community contribution, including the supporters' social support (SSoSup) and time span (STimSpa). Social support was defined as the total number of social support posts published by supporters, which was extracted through text classification. The time span was the number of days between the supporters' first and last posts.

\section{(3) Control variables}

To eliminate the interference of other factors, control variables were introduced. Supporters hope to be rewarded for their contributions. ${ }^{75}$ Therefore, receiving thanks can be regarded as a psychological reward, one of the external motivations for supporters' contribution. ${ }^{76}$ In addition, when supporters receive positive emotional feedback, they will feel that the help offered improves the emotions of other users, which increases their confidence and selfworth. Confidence and self-worth will increase their contributions. ${ }^{77}$ Moreover, reciprocity also increases supporters' contribution, ${ }^{78}$ and users who receive more support share more support. ${ }^{35,36}$ Therefore, the following control variables were introduced: thanks (Thx), emotional feedback (EmoFe) and received social support (ReSoSup).

Thanks (Thx) is defined as the proportion of posts received expressing thanks for the total number of replies received. Here, we use the Chinese word segmentation system to segment the posts and judge whether there are words expressing thanks in the posts. The above emotion calculation method is used to calculate the emotion value of the replies received as emotional feedback (EmoFe). Received social support (ReSoSup) is the proportion of social support received in terms of the total number of replies received. The social support posts here are identified by building text classifiers. The variable descriptions and statistical methods are listed in Table 3.

\section{Operationalization of Variables Influencing Ordinary Members' Participation}

(1) Independent variables

The independent variables were community response (Res) and emotion (Emo). Community response was defined as the total number of responses received by ordinary members. The calculation method for users' emotion value was the same as that described in Section 2.3.1.

\section{(2) Dependent variables}

The dependent variables were ordinary members' community participation, including members' posts (MPos) and time span (MTimSpa). Members' posts were defined 
Table 3 Descriptions of the Variables Used in the Analysis

\begin{tabular}{|c|c|c|c|}
\hline & Variable & Description & Methods \\
\hline \multirow[t]{3}{*}{$\begin{array}{l}\text { Dependent } \\
\text { Variable }\end{array}$} & $\begin{array}{l}\text { Supporters' social support } \\
\text { (SSoSup) }\end{array}$ & Total number of social support posts from supporters & Text classification \\
\hline & $\begin{array}{l}\text { Ordinary members' posts } \\
\text { (MPos) }\end{array}$ & Total number of posts from ordinary members & Statistics \\
\hline & STimSpa, MTimSpa & $\begin{array}{l}\text { Number of days between first and last posts of supporters or } \\
\text { ordinary members }\end{array}$ & Statistics \\
\hline \multirow{2}{*}{$\begin{array}{l}\text { Independent } \\
\text { Variable }\end{array}$} & Emotion (Emo) & Emotion value & Text classification, statistics \\
\hline & Response (Res) & Total number of responses & Statistics \\
\hline \multirow[t]{5}{*}{$\begin{array}{l}\text { Control } \\
\text { Variable }\end{array}$} & $\begin{array}{l}\text { Received social support } \\
\text { (ReSoSup) }\end{array}$ & $\begin{array}{l}\text { Proportion of social support received in terms of the total number } \\
\text { of replies received }\end{array}$ & Text classification \\
\hline & $\begin{array}{l}\text { Emotional feedback } \\
\text { (EmoFe) }\end{array}$ & Emotional value received & Text classification, statistics \\
\hline & Thanks (Thx) & $\begin{array}{l}\text { The proportion of thanks received in terms of the total number of } \\
\text { replies received }\end{array}$ & $\begin{array}{l}\text { Keyword extraction, } \\
\text { statistics }\end{array}$ \\
\hline & $\begin{array}{l}\text { Emotional differences } \\
\text { (EmoDif) }\end{array}$ & $\begin{array}{l}\text { The difference between the user's emotion value and the } \\
\text { emotional value received }\end{array}$ & Text classification, statistics \\
\hline & Response time (ReTim) & The average time interval between the user's post and the first reply & Statistics \\
\hline
\end{tabular}

as the total number of posts published by each member. Meanwhile, time span was defined as the number of days between a member's first and last posts.

\section{(3) Control variables}

Research has confirmed that obtaining social support is the main reason members participate in online health communities. ${ }^{52}$ Moreover, similar individuals are more likely to attract, trust and understand each other than dissimilar individuals, and are therefore more likely to share information and participate in discussions. ${ }^{44}$ In addition, long response delays seriously impact users' willingness to participate ${ }^{48}$ Therefore, the control variables included received social support (ReSoSup), emotional differences (EmoDif), and response time (ReTim).

Received social support (ReSoSup) is also defined as the proportion of social support received in terms of the total number of replies received. Emotional difference is defined as the difference between the user's emotion value and the emotional value received. Response time (ReTim) is expressed as the average time interval between the user's post and the first reply. Table 3 shows the descriptions of the variables used and the statistical methods.

\section{Econometrics Analysis}

Next, a regression model was used to analyze the data. First, we verified the effects of supporters' emotions and community response on supporters' contributions, including their social support and time span (Models 1 and 2). Then, we verified the effects of ordinary members' emotions and community response on ordinary members' participation, including the total number of posts and time span (Models 3 and 4). Regression equations for these analyses were developed for the UDC and MDC, and cross terms were used to test the effects of community differences on supporters' contributions (Models 5 and 6) and ordinary members' participation (Models 7 and 8). The equations are as follows:

Models 1 and 2:

$$
\begin{aligned}
\operatorname{SSoSup}_{i}, \operatorname{STimSpa}_{i}= & \beta_{0}+\beta_{1} * \text { Emo }_{i}+\beta_{2}+\operatorname{Res}_{i}+\beta_{3} \\
& * \text { Control }_{i}+\varepsilon_{i}+\mu_{i}
\end{aligned}
$$

Models 3 and 4:

$$
\begin{aligned}
\operatorname{MPos}_{i}, \text { MTimSpa }_{i}= & \beta_{0}+\beta_{1} * \text { Emo }_{i}+\beta_{2}+\operatorname{Res}_{i}+\beta_{3} \\
& * \text { Control }_{i}+\varepsilon_{i}+\mu_{i}
\end{aligned}
$$


Models 5 and 6:

$$
\begin{aligned}
& \text { SSoSup }_{i}, \text { STimSpa }_{i}=\beta_{0}+\beta_{1} * \text { Emo }_{i}+\beta_{2}+\operatorname{Res}_{i} \\
& \quad+\beta_{3} *{\text { Community } * \text { Emo }_{i}+\beta_{4} * \text { Community } * \operatorname{Res}_{i}}+\beta_{5} * \text { Control }_{i}+\varepsilon_{i}+\mu_{i}
\end{aligned}
$$

Models 7 and 8:

$$
\begin{aligned}
& \text { MPos }_{i}, \text { MTimSpa }_{i}=\beta_{0}+\beta_{1} * \text { Emo }_{i}+\beta_{2}+\operatorname{Res}_{i} \\
& \quad+\beta_{3} *{\text { Community } * \text { Emo }_{i}+\beta_{4} * \text { Community }}^{* \operatorname{Res}_{i}+\beta_{5} * \text { Control }_{i}+\varepsilon_{i}+\mu_{i}}
\end{aligned}
$$

We conducted a robustness check by adding or removing regressors to examine whether the core regression coefficient estimates were plausible and robust. ${ }^{79}$

\section{Results}

\section{Statistical Analysis of Community Users' Roles}

To distinguish the supporters and ordinary members in the two communities, we first built a text classifier to identify posts expressing social support. Subsequently, member profiles, defined by type of social support, were built and clustered. Figure 2 presents the optimal number of clusters obtained from the k-means clustering results. The optimal number of clusters for MDC and UDC was 3 (Table 4). The clustering centroids are the proportion of companionship and social support in each

\begin{tabular}{|c|c|c|c|}
\hline Community & $\begin{array}{l}\text { Centroids } \\
\text { Companionship, } \\
\text { Social Support) }\end{array}$ & Role & $\begin{array}{l}\text { Percentage of } \\
\text { Total Users } \\
\text { (Number) }\end{array}$ \\
\hline UDC & $\begin{array}{l}0.98678655 \\
0.01321345 \\
0.57570387, \\
0.42429613 \\
0.01285321, \\
0.98714679\end{array}$ & $\begin{array}{l}\text { Ordinary } \\
\text { members } \\
\text { Ordinary } \\
\text { members } \\
\text { Supporters }\end{array}$ & $\begin{array}{l}74.56 \%(190,410) \\
11.60 \%(29,664) \\
13.95 \%(35,668)\end{array}$ \\
\hline MDC & $\begin{array}{l}0.993236454 \\
0.00676354 \\
0.616835136 \\
0.383164864 \\
0.009252685 \\
0.990747315\end{array}$ & $\begin{array}{l}\text { Ordinary } \\
\text { members } \\
\text { Ordinary } \\
\text { members } \\
\text { Supporters }\end{array}$ & $\begin{array}{l}78.63 \%(72,948) \\
7.68 \%(7|2|) \\
13.70 \%(12,708)\end{array}$ \\
\hline
\end{tabular}
group. A higher proportion of social support in posts indicates a higher willingness to contribute and a higher level of expertise. ${ }^{54}$ Therefore, we define users who post and provide social support frequently as supporters.
Table 4 Descriptions of the Variables

Abbreviations: UDC, unmanaged depression-focused community; MDC, managed depression-focused community.

Users who provide social support less frequently and users who do not provide social support were classified as ordinary members.

After classifying the users of the two communities into supporters or ordinary members, we determined their online activity based on the "9-1 principle," which is based on the "90-9-1 principle." ${ }^{\prime 80}$ The 90-9-1 principle states that, in an online community, $90 \%$ of the participants are inactive (meaning most users only read the content and rarely post; such participants are referred to as "lurkers"), $9 \%$ of the participants edit content, and only $1 \%$ of the participants actively create new content. ${ }^{80}$ Transferring this principle into a 9:1 ratio, we defined the users who were ranked in the top $10 \%$ of the total number of posts in the community as the "posters," and the remaining $90 \%$ as "lurkers."
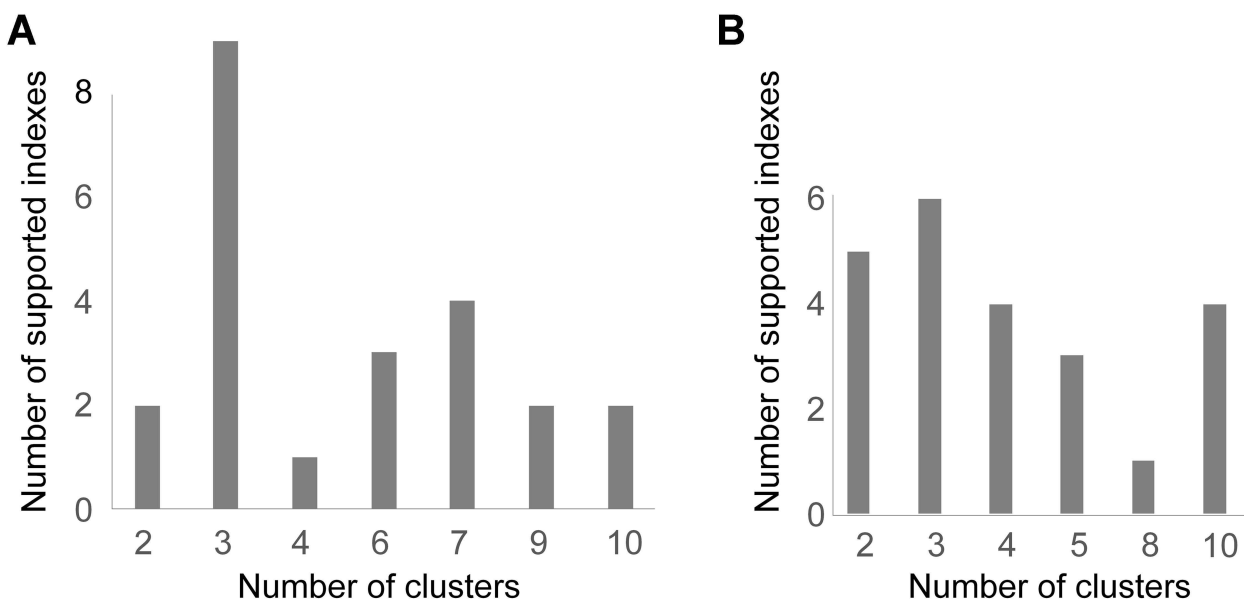

Figure 2 

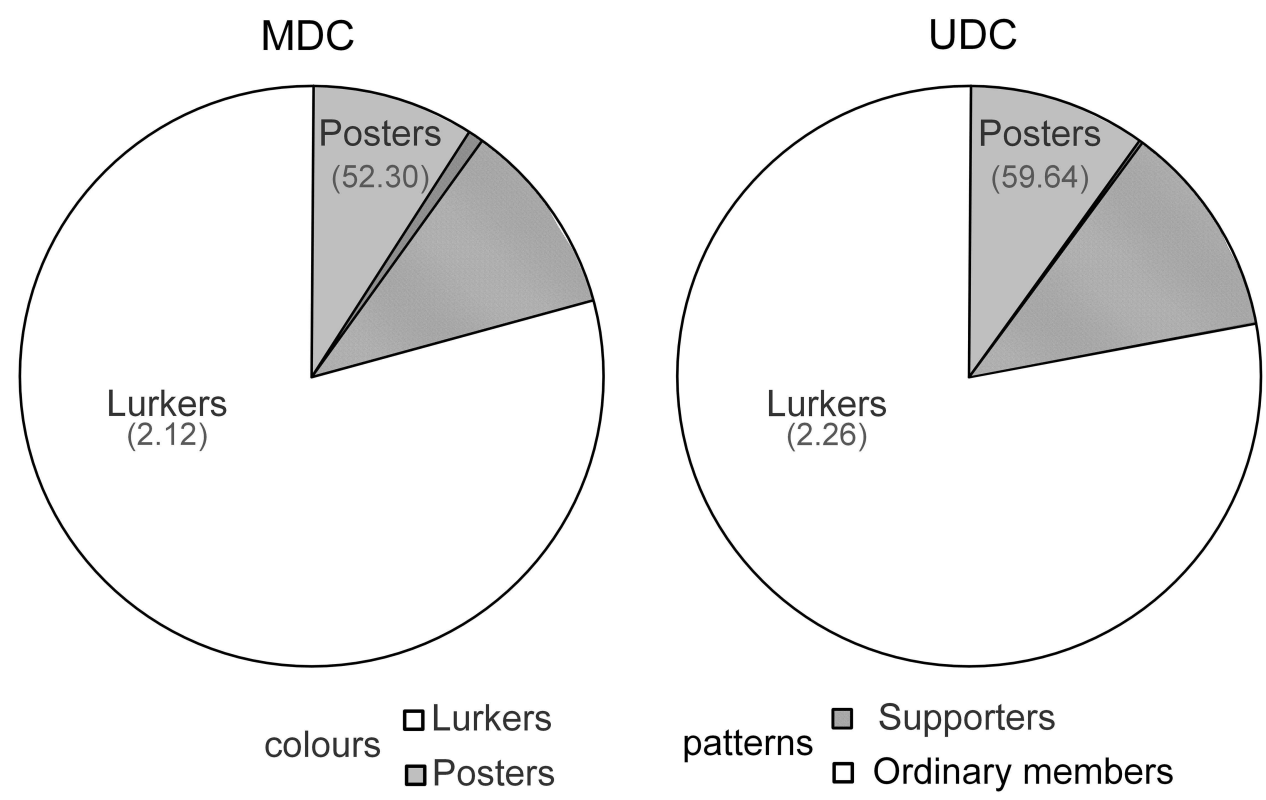

Figure 3

As seen in Figure 3, for the UDC the average number of posts from lurkers was 2.24 (1-11), and the average number of posts from posters was 59.64 (11-8723). The supporters accounted for only a small section of the posters. Meanwhile, for the MDC the average number of posts from lurkers was $2.12(1-10)$, and the average number of posts from posters was 52.30 (10-8867). The proportion of supporters among the posters was very small, but slightly higher than that for the UDC.

\section{Analysis of Factors Influencing User Participation in the Communities}

\section{Data Analysis}

Given that the variables varied in terms of their initial quantities, we standardized the dependent, independent, and control variables for the econometric analysis. STATA was used to analyze the data. Table 5 presents the descriptive statistics of the variables.

\section{Regression Results for the Supporters' Contribution}

First, we used a regression model to test the influence of supporters' emotion and community response on their social support, as well as the difference between the two communities with regard to the strength of this influence. The regression results (see Table 6) indicated that supporters' emotion had a positive and significant effect on the social support that they provide in communities $(\beta=0.006$, $\mathrm{p}<0.001$ in Model 1 [UDC], $\beta=0.017, \mathrm{p}<0.01$ in Model $2[\mathrm{MDC}])$. Cross terms were introduced into the model, and the model results consequently showed that there was no significant difference between the UDC and MDC regarding the effect of supporters' emotions on the social support they provide $(\beta=0.018, p>0.05$ in Model 3$)$. Nevertheless, in the UDC, response was found to have a significant and positive effect on supporters' social support $(\beta=0.799, \mathrm{P}<$ 0.001 in model 1 [UDC]). In the MDC, this effect was not significant $(\beta=0.013, \mathrm{P}>0.05$ in Model 2 [MDC]). Finally, for the UDC, the effect of community response on supporters' social support exceeded that of supporters' emotion on their social support.

We then used a regression model to test the effect of supporters' emotion and community response on supporters' time span in the community, as well as the difference between the two communities. The results (see Table 6) indicated that in the UDC, supporters' emotions had a negative and significant effect on their time span ( $\beta=$ $-0.025, \mathrm{p}<0.001$ in Model 4 [UDC]), whereas in the MDC, this effect was positive and significant $(\beta=0.027$, $\mathrm{p}<0.001$ in Model 5 [MDC]). In addition, in the UDC, response had a significant and positive effect on supporters' time span $(\beta=0.099, \mathrm{P}<0.001$ in model 4 [UDC]). Meanwhile, in the MDC, the effect of community response on supporters' time span was positive ( $\beta=0.065, \mathrm{P}>0.05$ in model $5[\mathrm{MDC}])$ but not significant. Finally, for the UDC, the effect of community response on supporters' time span outweighed that of supporters' emotion on their own time span. 
Table 5 Descriptive Statistics for the Variables

\begin{tabular}{|c|c|c|c|c|c|c|c|c|c|c|}
\hline & \multicolumn{5}{|l|}{ UDC } & \multicolumn{5}{|l|}{ MDC } \\
\hline & Mean & $\begin{array}{l}\text { Std. } \\
\text { Dev }\end{array}$ & Min & Max & VIF & Mean & $\begin{array}{l}\text { Std. } \\
\text { Dev }\end{array}$ & Min & Max & VIF \\
\hline \multicolumn{11}{|l|}{ Supporters } \\
\hline SSoSup & 2.070 & 13.280 & 1 & 1229 & - & 2.313 & 32.142 & 1 & 3243 & - \\
\hline STimSpa & 1.251 & 6.669 & 1 & 1212 & - & 1.343 & 5.242 & 1 & 310 & - \\
\hline Emo & 0.722 & 0.572 & -1 & 1 & 1.00 & 0.423 & 0.636 & -1 & 1 & 1.04 \\
\hline Res & 0.400 & 3.563 & 0 & 250 & 4.28 & 0.428 & 4.204 & 0 & 312 & 1.09 \\
\hline ReSoSup & 0.043 & 0.191 & 0 & 1 & 4.34 & 0.024 & 0.131 & 0 & I & 1.36 \\
\hline EmoFe & 0.051 & 0.309 & -1 & I & 1.54 & 0.004 & 0.101 & -1 & 1 & 1.29 \\
\hline Thx & 0.046 & 0.195 & 0 & 1 & 1.49 & 0.002 & 0.039 & 0 & 1 & 1.06 \\
\hline \multicolumn{11}{|l|}{ Ordinary members } \\
\hline MPos & 8.930 & 56.318 & 1 & 8723 & - & 7.935 & 56.798 & 1 & 8867 & - \\
\hline MTimSpa & 3.394 & 9.864 & 1 & 630 & - & 3.285 & 10.688 & 1 & 584 & - \\
\hline Emo & -0.505 & 0.558 & -1 & 1 & 1.46 & -0.260 & 0.495 & -1 & 1 & 1.86 \\
\hline Res & 1.647 & 10.689 & 0 & 1416 & 1.06 & 4.521 & 27.188 & 0 & 2557 & 1.77 \\
\hline ReSoSup & 0.120 & 0.284 & 0 & I & 1.92 & 0.0768 & 0.199 & 0 & 1 & 1.57 \\
\hline EmoDif & 0.732 & 0.491 & 0 & 2 & 1.72 & 0.402 & 0.427 & 0 & 2 & 1.53 \\
\hline ReTim & 253.129 & 167.786 & 0 & 365 & 1.71 & 274.875 & 154.529 & 0 & 365 & 1.09 \\
\hline
\end{tabular}

Abbreviations: Emo, emotion; EmoDif, emotional differences; EmoFe, emotional feedback; UDC, unmanaged depression-focused community; MDC, managed depressionfocused community; MPos, Total number of posts from ordinary members; MTimSpa, Number of days between first and last posts of ordinary members; Res, response; ReSoSup, received social support; ReTim, response time; SSoSup, Total number of social support posts from supporters; STimSpa, Number of days between first and last posts of supporters; Std. Dev, standard deviation; Thx, thanks; VIF, variance inflation factor.

The effect of community response on supporters' social support differed significantly between the two community types. In addition, there were significant differences between the two communities regarding the effect of supporters' emotions and community response on supporters' time span.

\section{Regression Results for Ordinary Members' Participation}

We used a regression model to test the influence of ordinary members' emotions and community response on the number of posts by ordinary members, as well as the difference between the two communities with respect to the strength of this influence. Table 7 presents the estimation results from the regression analysis. These results show that in the UDC, ordinary members' emotions were negatively associated with their posts $(\beta=$ $-0.008, \mathrm{p}<0.001$ in Model 1 [UDC]), while in the MDC, ordinary members' emotions were positively associated with their posts $(\beta=0.026, p<0.001$ in Model 2 $[\mathrm{MDC}])$. Meanwhile, community response had a significant and positive effect on ordinary members' posts $(\beta=0.833, \mathrm{p}<0.001$ in Model 1 (UDC), $\beta=$ $0.402, \mathrm{p}<0.001$ in Model $2[\mathrm{MDC}]$ ); this effect was greater in the UDC $(\beta=-1.045, \mathrm{p}<0.001$ in Model 3$)$.
Next, we used a regression model to test the effect of ordinary members' emotions and community response on ordinary members' time span, as well as the difference in this regard between the two communities. The regression results (see Table 7) indicated that, in the UDC, ordinary members' emotions had a negative and significant effect on their time span $(\beta=-0.040, \mathrm{p}<0.001$ in Model 4 [UDC]), while in the MDC, ordinary members' emotions had a positive and significant effect on their time span $(\beta=0.044, p<0.001$ in Model $5[\mathrm{MDC}])$. Furthermore, community response showed a significant and positive effect on ordinary members' time $\operatorname{span}(\beta=0.528, \mathrm{p}<0.001$ in Model 4 [UDC], $\beta=0.396$, $\mathrm{p}<0.001$ in Model 5 [MDC]); this effect was greater in the UDC ( $\beta=-0.556, p<0.001$ in Model 6$)$.

The effect of ordinary members' emotions and community response on their posts and time span differed significantly across the two community types.

\section{Robustness Checks}

We tested the robustness of the main effects model by varying the control variables. The results of the robustness checks are shown in Tables 8 and 9 (Table 8 is for supporters and Table 9 for ordinary members). After removing some control variables, the coefficients and significance of the main effect model do not change, which is 
Table 6 Regression Results for the Supporters' Contributions

\begin{tabular}{|c|c|c|c|c|c|c|}
\hline & \multicolumn{3}{|c|}{ Social Support } & \multicolumn{3}{|c|}{ Time Span } \\
\hline & Model I & Model 2 & Model 3 & Model 4 & Model 5 & Model 6 \\
\hline & UDC & MDC & Interactive & UDC & MDC & Interactive \\
\hline Emo & $\begin{array}{c}0.006 * * * \\
(0.001)\end{array}$ & $\begin{array}{l}0.017^{* *} \\
(0.006)\end{array}$ & $\begin{array}{c}0.004^{* * *} \\
(0.001)\end{array}$ & $\begin{array}{c}-0.025^{* * *} \\
(0.004)\end{array}$ & $\begin{array}{c}0.027^{* * *} \\
(0.007)\end{array}$ & $\begin{array}{c}-0.030 * * * \\
(0.005)\end{array}$ \\
\hline Res & $\begin{array}{c}0.799 * * * \\
(0.073)\end{array}$ & $\begin{array}{c}0.013 \\
(0.007)\end{array}$ & $\begin{array}{c}0.555^{* * *} \\
(0.05 I)\end{array}$ & $\begin{array}{c}0.099 * * * \\
(0.025)\end{array}$ & $\begin{array}{c}0.065 \\
(0.041)\end{array}$ & $\begin{array}{c}0.122^{* * *} \\
(0.030)\end{array}$ \\
\hline ReSoSup & $\begin{array}{c}-0.05 I^{* * *} \\
(0.012)\end{array}$ & $\begin{array}{c}0.003 \\
(0.004)\end{array}$ & $\begin{array}{c}-0.025 * * * \\
(0.007)\end{array}$ & $\begin{array}{c}0.06 I^{* * * *} \\
(0.010)\end{array}$ & $\begin{array}{c}0.005 \\
(0.012)\end{array}$ & $\begin{array}{c}0.055^{* * * *} \\
(0.009)\end{array}$ \\
\hline EmoFe & $\begin{array}{c}0.036 * * * \\
(0.009)\end{array}$ & $\begin{array}{c}0.004 \\
(0.005)\end{array}$ & $\begin{array}{c}0.017^{* * *} \\
(0.005)\end{array}$ & $\begin{array}{c}-0.020 * \\
(0.010)\end{array}$ & $\begin{array}{c}0.025 \\
(0.015)\end{array}$ & $\begin{array}{l}-0.015 \\
(0.009)\end{array}$ \\
\hline Thx & $\begin{array}{c}-0.050 * * * \\
(0.012)\end{array}$ & $\begin{array}{l}0.016^{*} \\
(0.008)\end{array}$ & $\begin{array}{c}-0.026 * * * \\
(0.007)\end{array}$ & $\begin{array}{c}0.04 I^{* * * *} \\
(0.009)\end{array}$ & $\begin{array}{c}0.043 \\
(0.024)\end{array}$ & $\begin{array}{c}0.04 I^{* * * *} \\
(0.009)\end{array}$ \\
\hline Community & & & $\begin{array}{c}0.013 \\
(0.018)\end{array}$ & & & $\begin{array}{c}-0.154^{* * *} \\
(0.006)\end{array}$ \\
\hline Community* Emo & & & $\begin{array}{c}0.018 \\
(0.010)\end{array}$ & & & $\begin{array}{c}0.038 * * * \\
(0.005)\end{array}$ \\
\hline Community* Res & & & $\begin{array}{c}-0.530 * * * \\
(0.052)\end{array}$ & & & $\begin{array}{c}-0.127^{* * *} \\
(0.030)\end{array}$ \\
\hline Constant & $\begin{array}{c}0.000 \\
(0.003)\end{array}$ & $\begin{array}{l}-0.000 \\
(0.009)\end{array}$ & $\begin{array}{l}-0.001 \\
(0.002)\end{array}$ & $\begin{array}{c}0.000 \\
(0.005)\end{array}$ & $\begin{array}{l}-0.000 \\
(0.009)\end{array}$ & $\begin{array}{c}0.044 * * * \\
(0.006)\end{array}$ \\
\hline $\begin{array}{l}\text { R-squared } \\
N \\
\mathrm{~F}\end{array}$ & $\begin{array}{c}0.624 \\
35668 \\
191.558\end{array}$ & $\begin{array}{c}0.001 \\
12,708 \\
3.934334\end{array}$ & $\begin{array}{c}0.202 \\
48,376 \\
103.0204\end{array}$ & $\begin{array}{c}0.017 \\
35,668 \\
32.20993\end{array}$ & $\begin{array}{c}0.007 \\
12,708 \\
4.320892\end{array}$ & $\begin{array}{c}0.022 \\
48,376 \\
95.267\end{array}$ \\
\hline
\end{tabular}

Notes: ${ }^{*} p<0.05,{ }^{*} \mathrm{p}<0.01,{ }^{* * *} \mathrm{p}<0.001$. Bold values: Highlight the coefficients of independent variables and cross terms in the models.

Abbreviations: Emo, emotion; EmoFe, emotional feedback; UDC, unmanaged depression-focused community; MDC, managed depression-focused community; Res, response; ReSoSup, received social support; Thx, thanks.

consistent with the presentations in Tables 6 and 7. This proves the rationality and reliability of the models.

\section{Discussion}

Active user participation is essential for online communities' sustainability. ${ }^{26}$ This study investigated participation in ODCs by classifying the users of an MDC and a UDC into supporters and ordinary members according to the content of their posts. Then, we examined and compared the online behavior of the supporters and ordinary members of the two communities.

First, applying the 9-1 principle, ${ }^{80}$ we found that both communities (especially the UDC) had relatively few active supporters. Many supporters may be professional mental health service staff, who generally have a high level of knowledge about depression and can provide informational and emotional support to the community members. Other supporters might be people with experience of depression who wish to share their knowledge regarding the condition and its treatment with community members and also provide encouragement. A low level of supporter activity may result in community members being unable to obtain effective help.

Our results show that community response positively influenced supporters' contributions in the UDC, but had no significant impact in the MDC. MDC managers endeavor to forge relationships with professional support groups $^{81}$ and encourage supporters from such groups to provide support actively and continuously for community members, but this does not occur in the UDCs, where community response is the most important factor influencing supporters' contributions in the UDCs; it enables 
Table 7 Regression Results for the Ordinary Members' Participation

\begin{tabular}{|c|c|c|c|c|c|c|}
\hline & \multicolumn{3}{|c|}{ Post } & \multicolumn{3}{|c|}{ Time Span } \\
\hline & Model I & Model 2 & Model 3 & Model 4 & Model 5 & Model 6 \\
\hline & UDC & MDC & Interactive & UDC & MDC & Interactive \\
\hline Emo & $\begin{array}{c}-0.008^{* * *} \\
(0.001)\end{array}$ & $\begin{array}{c}0.026 * * * \\
(0.002)\end{array}$ & $\begin{array}{c}-0.01 \mathrm{I} \text { 粐 } \\
(0.00 \mathrm{I})\end{array}$ & $\begin{array}{c}-0.040 \text { *** } \\
(0.001)\end{array}$ & $\begin{array}{c}0.044^{* * *} \\
(0.003)\end{array}$ & $\begin{array}{c}-0.036 \text { *** } \\
(0.001)\end{array}$ \\
\hline Res & $\begin{array}{c}0.833^{* * *} \\
(0.047)\end{array}$ & $\begin{array}{c}0.402^{* * *} \\
(0.087)\end{array}$ & $\begin{array}{l}\text { I.302*** } \\
(\mathbf{0 . 0 7 4 )}\end{array}$ & $\begin{array}{c}0.528 * * * \\
(0.048)\end{array}$ & $\begin{array}{c}0.396 * * * \\
(0.050)\end{array}$ & $\begin{array}{c}0.813 * * * \\
(0.074)\end{array}$ \\
\hline ReSoSup & $\begin{array}{c}0.008 * * * \\
(0.001)\end{array}$ & $\begin{array}{l}-0.005 \\
(0.004)\end{array}$ & $\begin{array}{l}0.004^{* *} \\
(0.001)\end{array}$ & $\begin{array}{c}0.036 * * * \\
(0.002)\end{array}$ & $\begin{array}{c}-0.017^{* * *} \\
(0.005)\end{array}$ & $\begin{array}{c}0.025^{* * *} \\
(0.002)\end{array}$ \\
\hline EmoDif & $\begin{array}{c}-0.008 * * \\
(0.003)\end{array}$ & $\begin{array}{c}-0.014 * * * \\
(0.003)\end{array}$ & $\begin{array}{c}-0.012^{* * *} \\
(0.003)\end{array}$ & $\begin{array}{c}-0.060 * * * \\
(0.003)\end{array}$ & $\begin{array}{c}-0.035^{* * *} \\
(0.003)\end{array}$ & $\begin{array}{c}-0.054^{* * *} \\
(0.002)\end{array}$ \\
\hline ReTim & $\begin{array}{l}0.03 I^{* *} \\
(0.011)\end{array}$ & $\begin{array}{l}-0.033 \\
(0.020)\end{array}$ & $\begin{array}{c}0.015 \\
(0.010)\end{array}$ & $\begin{array}{c}-0.122^{* * * *} \\
(0.011)\end{array}$ & $\begin{array}{c}-0.112^{* * *} \\
(0.014)\end{array}$ & $\begin{array}{c}-0.116^{* * *} \\
(0.009)\end{array}$ \\
\hline Community & & & $\begin{array}{c}-0.126^{* * *} \\
(0.007)\end{array}$ & & & $\begin{array}{c}-0.108^{* * *} \\
(0.006)\end{array}$ \\
\hline Community* Emo & & & $\begin{array}{c}0.038^{* * *} \\
(0.002)\end{array}$ & & & $\begin{array}{c}0.084 * * * \\
(0.003)\end{array}$ \\
\hline Community* Res & & & $\begin{array}{c}-1.045^{* * *} \\
(\mathbf{0 . 0 8 8 )}\end{array}$ & & & $\begin{array}{c}-0.556 \text { *** } \\
(0.078)\end{array}$ \\
\hline Constant & $\begin{array}{l}-0.000 \\
(0.001)\end{array}$ & $\begin{array}{l}-0.000 \\
(0.003)\end{array}$ & $\begin{array}{c}0.065^{* * *} \\
(0.004)\end{array}$ & $\begin{array}{l}-0.000 \\
(0.002)\end{array}$ & $\begin{array}{l}-0.000 \\
(0.003)\end{array}$ & $\begin{array}{c}0.040 * * * \\
(0.004)\end{array}$ \\
\hline $\begin{array}{l}\text { R-squared } \\
N \\
F\end{array}$ & $\begin{array}{c}0.685 \\
220074 \\
2151.305\end{array}$ & $\begin{array}{c}0.170 \\
80,069 \\
221.7659\end{array}$ & $\begin{array}{c}0.545 \\
300,143 \\
|4| 2.408\end{array}$ & $\begin{array}{c}0.332 \\
220,074 \\
2227.074\end{array}$ & $\begin{array}{c}0.194 \\
80,069 \\
392.8906\end{array}$ & $\begin{array}{c}0.290 \\
300,143 \\
1557.97\end{array}$ \\
\hline
\end{tabular}

Notes: $*_{p}<0.05$, ** $p<0.01$, *** $<0.00$ I. Bold values: Highlight the coefficients of independent variables and cross terms in the models.

Abbreviations: Emo, emotion; EmoDif, emotional differences; UDC, unmanaged depression-focused community; MDC, managed depression-focused community; Res, response; ReSoSup, received social support; ReTim, response time.

supporters to feel that their contributions are recognized, which can enhance their sense of self-worth and motivate them to make further contributions. Emotional characteristics also affected supporters' contributions, though these effects were very small and significant. Supporters expressing positive emotions provided more social support in both communities, but they contributed for a longer time in the MDC. Supporters expressing negative emotions spend more time than expressing positive emotions in the UDC. UDC supporters expressing negative emotions may have comprised people who had experienced or were experiencing depression. Thus, they may not have had a high level of expertise, but they tended to have longer engagement with the community.

Finally, community response is the most important factor related to increasing ordinary members' participation, and this effect is stronger in UDCs. The main purpose of ordinary members' participation in the MDCs may be to seek professional health support, while the primary motivation to participate in the UDCs may relate more to a desire for self-expression and communication with others. UDCs enable ordinary members to communicate freely, and community response encourages ordinary members to express and exchange health-related information and emotions more actively; this allows such users to establish social relationships in online communities, which may be difficult for them to achieve in real life. In addition, there are differences in community engagement among ordinary members with different emotional characteristics. Ordinary members expressing negative emotions are found to be more likely to participate in the UDCs, while ordinary members expressing positive 


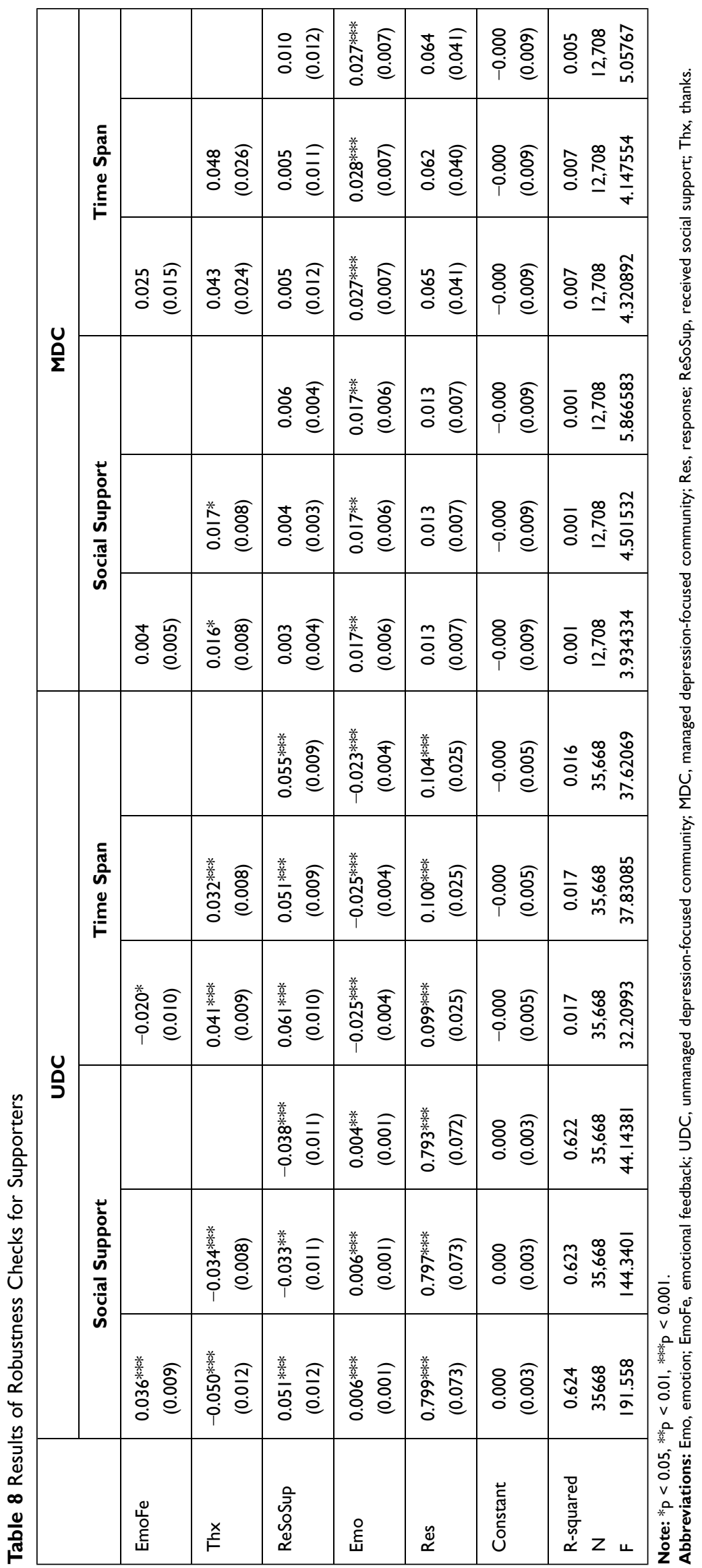




\begin{tabular}{|c|c|c|c|c|c|c|c|c|}
\hline \multirow{6}{*}{ 克 } & \multirow{3}{*}{ 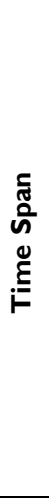 } & & & 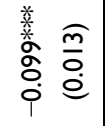 & 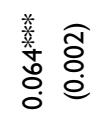 & 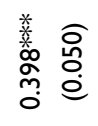 & 웅 & 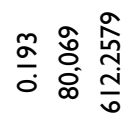 \\
\hline & & & 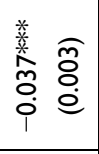 & $\frac{x_{*}^{*}}{\frac{m}{0}}$ & 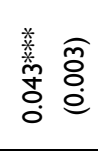 & 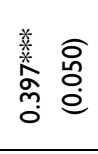 & $\begin{array}{l}\circ \\
0 \\
0 \\
i \\
i\end{array}$ & 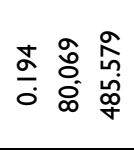 \\
\hline & & 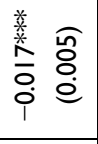 & 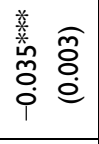 & 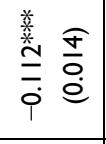 & 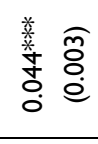 & 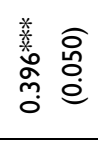 & $\begin{array}{l}0 \\
0 \\
0 \\
i\end{array}$ & 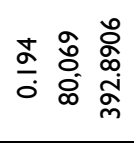 \\
\hline & \multirow{3}{*}{$\begin{array}{l}\ddot{\hat{~}} \\
\stackrel{0}{0}\end{array}$} & & & 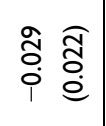 & 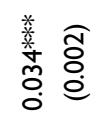 & 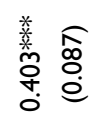 & 。 & 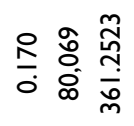 \\
\hline & & & 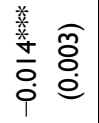 & 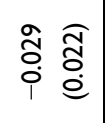 & 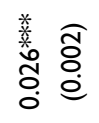 & 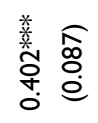 & 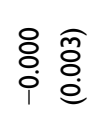 & 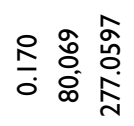 \\
\hline & & 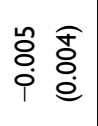 & 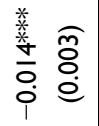 & 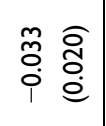 & 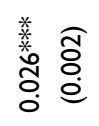 & 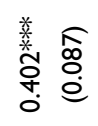 & 웅 & 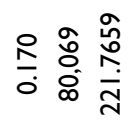 \\
\hline \multirow{6}{*}{ ư } & \multirow{3}{*}{ 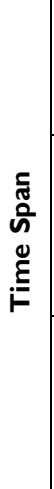 } & & & 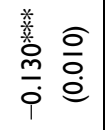 & $\begin{array}{l}\text { 粒 } \overline{\bar{\alpha}} \\
\text { 웅 }\end{array}$ & 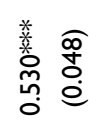 & o ठ & 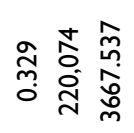 \\
\hline & & & 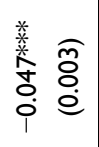 & 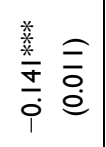 & 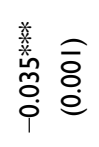 & 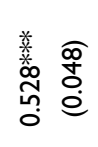 & 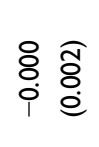 & 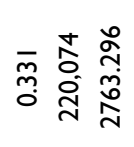 \\
\hline & & 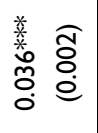 & 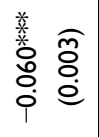 & 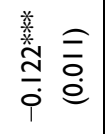 & $\begin{array}{l}\text { 类 } \\
\text { ôे } \\
0 \\
0 \\
i\end{array}$ & 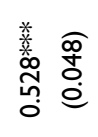 & o ठ & 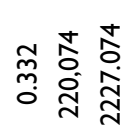 \\
\hline & \multirow{3}{*}{$\begin{array}{l}\ddot{\Delta} \\
0\end{array}$} & & & 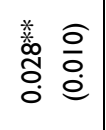 & 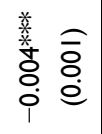 & 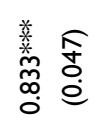 & 웅 & 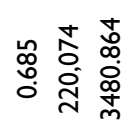 \\
\hline & & & 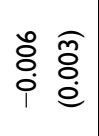 & 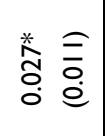 & 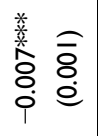 & 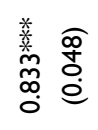 & $\begin{array}{l}8 \\
\stackrel{0}{0} \\
i \\
i\end{array}$ & 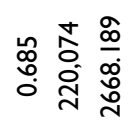 \\
\hline & & 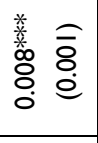 & 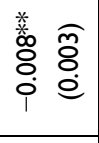 & 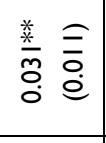 & 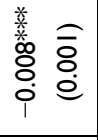 & 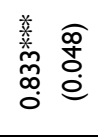 & $\begin{array}{l}0 \\
\text { o } \\
i \\
i\end{array}$ & 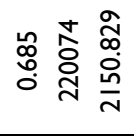 \\
\hline & & 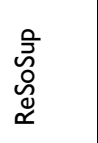 & 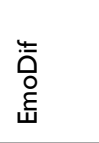 & 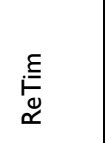 & Е̊ & $\approx$ & 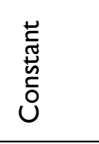 & 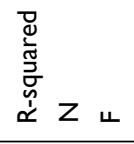 \\
\hline
\end{tabular}


emotions are more likely to participate in the MDCs. People with more negative emotions tend to have higher levels of depressive symptoms, indicating that they may perceive a deeper level of stigma; thus, they attach more importance to privacy when disclosing health information. ${ }^{67-69}$ The anonymous and less-restrictive nature of the UDCs allows such people to feel less at risk when disclosing personal problems. In contrast, individuals with positive emotions tend to be able to manage their condition positively, and the main purpose of their participation in online communities is to obtain knowledge and experience regarding depression. Compared to UDCs, MDCs have more professional, experienced, and knowledgeable supporters, who can consequently provide more effective help and suggestions; thus, individuals with positive emotions are more willing to participate in MDCs. Like general MDCs, the MDC in our study has language restrictions. Extreme negative statements, such as those regarding suicide and self-harm, are not allowed to be discussed, which is an important factor hindering the participation of negative-emotion users in MDCs.

Our research extends previous theoretical work by considering the effect of differences in communitymanagement type on the online behaviors of ODCs users. The empirical results show that emotion and community response influenced supporters' level of contribution and ordinary members' level of participation and that there is a significant difference between UDCs and MDCs in terms of effects on users' online behaviors. These results improve the understanding of user behaviors in ODCs.

Our results have important practical significance for designers and managers of ODCs and mental health services in China. First, it is important for ODCs to motivate supporters to continuously contribute and members to actively participate. Our empirical results show that community response is the most important factor motivating online behavior of both supporters and ordinary members, especially in UDCs. This difference of effect might be due to the structural differences between the MDC and UDC in our study (ie, the UDC was a single comment thread following one post, and the MDC contained posts and comments). Compared to the MDC, the dialogue between users is easier to see in the UDC, attracting them to join the discussion. Thus, community designers can increase the opportunity for multiple interactions among users by improving the convenience of interaction and the visibility of interactive content.
Second, as discussed in previous studies, a correlation exists between problematic Internet use and depression. ${ }^{23}$ Given the potential negative consequences of discussing harmful topics such as suicide, MDC managers often develop a set of community norms and language restrictions. While this ensures a positive community environment, it may drive away some users with higher levels of depressive symptoms who need more help from support groups and feel the need to express negative emotions. ${ }^{67-}$ ${ }^{69}$ MDC managers should consider the need of depressed people to express negative emotions and consider appropriately liberalizing language restrictions. Previous research has consistently supported the importance of accepting and experiencing feelings, including negative emotions. ${ }^{82}$ Online communities should provide opportunities for individuals to express and discuss their thoughts and feelings.

Finally, considering the negative risks caused by liberalized language restrictions, as in the UDCs, support groups should monitor the content of community posts by establishing text monitors. In the case of extremely negative emotional posts, such as posts referring to suicide, psychological counseling services should be provided to the poster as soon as possible, which may reduce the incidence of harmful behaviors such as suicide. UDC attracts more depressed people with negative emotions than MDC. Faced with China's huge population and the scarcity and imbalance of mental health services, UDCs present an opportunity to help people with depression who are undiagnosed or untreated, at a low cost. Thus, it is important to mobilize professional support groups into UDCs to disseminate correct mental health knowledge and help members better cope with depression.

This study has a few limitations. First, the explained variance in Models 2 and 4-6 for the supporters is low. Due to limited data availability, variables such as network structure and demographic characteristics that may affect online behavior are not included in the model. These variables should be considered in future research, more indicators should be developed to investigate influencing factors, and the impact of these differences based on community-management type should be explored. Second, our research was limited to data retrieved from one MDC and one UDC that are popular and representative in China. More data from other online depression communities are needed to test whether our findings are generalizable. 


\section{Conclusion}

We explored supporters' contributions and ordinary members' participation in ODCs and considered the effects of community-management types on online behaviors. The results indicate that community response is the most important factor affecting supporters' contributions and ordinary members' participation, especially for UDC. Ordinary members expressing positive emotions are more active in the MDC, while those expressing negative emotions are more active in UDC. In addition, emotion also affects the supporters' contributions. Supporters expressing positive emotions post more social supportive comments. They can provide continuous support for members in MDC, but do not stay long in UDC.

The findings could help improve design and management of ODCs, as well as help mental health service staff better help people with depression. Opportunities for multiple interactions can be increased by improving the convenience of interaction and the visibility of interactive content, to promote the supporters' continuous contribution and the members' active participation. MDCs can increase participation among people with negative emotions by appropriately liberalizing language restrictions. Text monitors can be established to identify risk factors to reduce the incidence of suicide. Professional support groups can be introduced in the UDCs to popularize mental health knowledge and help members cope with their illness positively.

The research has a few limitations, such as that the explained variance of some models is low. Due to limited data availability, variables such as network structure and demographic characteristics that may affect online behavior are not included in the model. Nonetheless, our findings enhance the understanding of current ODCs.

\section{Funding}

This study was funded by the National Natural Science Foundation of China (Grant Nos. 71774041 and 71531013). The authors wish to express their sincere appreciation to the editors and reviewers of this paper.

\section{Disclosure}

The authors report no conflicts of interest in this work.

\section{References}

1. Brundtland GH. Mental Health: A Call for Action by World Health Ministers. Geneva: World Health Organization; 2014.
2. Andrews G, Issakidis C, Carter G. Shortfall in mental health service utilisation. $B r J$ Psychiatry. 2001;179(5):417-425. doi:10.1192/ bjp.179.5.417

3. De Choudhury M, De S. Mental health discourse on reddit: self-disclosure, social support, and anonymity. In: Proceedings of the International AAAI Conference on Web and Social Media; 2014:8.

4. Powell J, Clarke A. Information in mental health: qualitative study of mental health service users. Health Expect. 2006;9(4):359-365. doi:10.1111/j.1369-7625.2006.00403.x

5. Goffman E. Stigma: notes on the management of spoiled identity. Simon and Schuster; 2009.

6. Bargh JA, McKenna KYA, Fitzsimons GM. Can you see the real me? Activation and expression of the" true self" on the Internet. $J$ Soc Issues. 2002;58(1):33-48. doi:10.1111/1540-4560.00247

7. Houston TK, Cooper LA, Ford DE. Internet support groups for depression: a 1-year prospective cohort study. Am J Psychiatry. 2002;159(12):2062-2068. doi:10.1176/appi.ajp.159.12.2062

8. Rasheduzzaman M, Al Mamun F, Faruk MO, et al. Depression in Bangladeshi university students: the role of sociodemographic, personal, and familial psychopathological factors. Perspect Psychiatr Care. 2021. doi:10.1111/ppc.12722

9. Mamun MA, Naher S, Moonajilin MS, et al. Depression literacy and awareness programs among Bangladeshi students: an online survey. Heliyon. 2020;6(9):e04901. doi:10.1016/j.heliyon.2020.e04901

10. Hausner H, Hajak G, Spieß1 H. Gender differences in help-seeking behavior on two internet forums for individuals with self-reported depression. Gend Med. 2008;5(2):181-185. doi:10.1016/j.genm.20 08.05.008

11. Pestello FG, Davis-Berman J. Taking anti-depressant medication: a qualitative examination of internet postings. J Ment Health. 2008;17(4):349-360. doi:10.1080/09638230701498333

12. Fekete $\mathrm{S}$. The Internet-a new source of data on suicide, depression and anxiety: a preliminary study. Arch Suicide Res. 2002;6 (4):351-361. doi:10.1080/13811110214533

13. Salem DA, Bogat GA, Reid C. Mutual help goes on-line. J Community Psychol. 1997;25(2):189-207. doi:10.1002/(SICI) 1520-6629(199703)25:2<189::AID-JCOP7>3.0.CO;2-T

14. Nguyen T, Venkatesh S, Phung D. Textual cues for online depression in community and personal settings. Springer, Cham. 2016:19-34. doi:10.1007/978-3-319-49586-6 2

15. Tang J, Yu G, Yao X. A comparative study of online depression communities in China. Int $J$ Environ Res Public Health. 2020;17 (14):5023. doi:10.3390/ijerph17145023

16. Ba S, Wang L. Digital health communities: the effect of their motivation mechanisms. Decis Support Syst. 2013;55(4):941-947. doi:10. 1016/j.dss.2013.01.003

17. Kallinikos J, Tempini N. Patient data as medical facts: social media practices as a foundation for medical knowledge creation. Inf Syst Res. 2014;25(4):817-833. doi:10.1287/isre.2014.0544

18. Miller JK, Gergen KJ. Life on the line: the therapeutic potentials of computer mediated conversation. J Marital Fam Ther. 1998;24 (2):189-202. doi:10.1111/j.1752-0606.1998.tb01075.x

19. Burke M. Reading, writing, relationships: the impact of social network sites on relationships and well-being. Carnegie Mellon University; 2012.

20. Griffiths KM, Calear AL, Banfield MA, et al. Systematic review on Internet Support Groups (ISGs) and depression (2): what is known about depression ISGs?. J Med Internet Res. 2009;11(3):41. doi:10. 2196/jmir.1303

21. Manicavasagar V, Horswood D, Burckhardt R, et al. Feasibility and effectiveness of a web-based positive psychology program for youth mental health: randomized controlled trial. J Med Internet Res. 2014;16(6):3176. doi:10.2196/jmir.3176

22. Al Mamun MA, Griffiths MD. The association between Facebook addiction and depression: a pilot survey study among Bangladeshi students. Psychiatry Res. 2019;271:628-633. doi:10.1016/j.psychres. 2018.12.039 
23. Mamun MA, Hossain MS, Siddique AB, et al. Problematic internet use in Bangladeshi students: the role of socio-demographic factors, depression, anxiety, and stress. Asian J Psychiatr. 2019;44:48-54. doi:10.1016/j.ajp.2019.07.005

24. Mamun MA, Hossain MS, Moonajilin MS, et al. Does loneliness, self-esteem and psychological distress correlate with problematic internet use? A Bangladeshi survey study. Asia Pac Psychiatry. 2020;12(2):e12386. doi:10.1111/appy.12386

25. Maher CA, Lewis LK, Ferrar K, et al. Are health behavior change interventions that use online social networks effective? A systematic review. J Med Internet Res. 2014;16(2):40. doi:10.2196/jmir.2952

26. Ma WW, Chan A. Knowledge sharing and social media: altruism, perceived online attachment motivation, and perceived online relationship commitment. Comput Human Behav. 2014;39:51-58. doi:10. 1016/j.chb.2014.06.015

27. Lin TC, Hsu JSC, Cheng HL, Chiu CM. Exploring the relationship between receiving and offering online social support: a dual social support model. Inf Manag. 2015;52(3):371-383. doi:10.1016/j. im.2015.01.003

28. Malinen S. Understanding user participation in online communities: a systematic literature review of empirical studies. Comput Human Behav. 2015;46:228-238. doi:10.1016/j.chb.2015.01.004

29. Amichai-Hamburger Y, Vinitzky G. Social network use and personality. Comput Human Behav. 2010;26(6):1289-1295. doi:10. 1016/j.chb.2010.03.018

30. Moore K, McElroy JC. The influence of personality on Facebook usage, wall postings, and regret. Comput Human Behav. 2012;28 (1):267-274. doi:10.1016/j.chb.2011.09.009

31. Muscanell NL, Guadagno RE. Make new friends or keep the old: gender and personality differences in social networking use. Comput Human Behav. 2012;28(1):107-112. doi:10.1016/j.chb.2011.08.016

32. Ross C, Orr ES, Sisic M, et al. Personality and motivations associated with Facebook use. Comput Human Behav. 2009;25(2):578-586. doi:10.1016/j.chb.2008.12.024

33. Cullen R, Morse S. Who's contributing: do personality traits influence the level and type of participation in online communities. In: 2011 44th Hawaii International Conference on System Sciences. IEEE; 2011:1-11.

34. Chen J, Shen XL. Consumers' decisions in social commerce context: an empirical investigation. Decis Support Syst. 2015;79:55-64. doi:10.1016/j.dss.2015.07.012

35. Yan Z, Wang T, Chen Y, Zhang H. Knowledge sharing in online health communities: a social exchange theory perspective. Inf Manag 2016;53(5):643-653. doi:10.1016/j.im.2016.02.001

36. Zhang X, Liu S, Deng Z, Chen X. Knowledge sharing motivations in online health communities: a comparative study of health professionals and normal users. Comput Human Behav. 2017;75:797-810. doi:10.1016/j.chb.2017.06.028

37. Zhang X, Liu S, Chen X, Wang L, Gao B, Zhu Q. Health information privacy concerns, antecedents, and information disclosure intention in online health communities. Inf Manag. 2018;55(4):482-493. doi:10.1016/j.im.2017.11.003

38. Han JJ, Zheng RJ, Xu Y. The effect of individual needs, trust and identification in explaining participation intentions in virtual communities. In: 2007 40th Annual Hawaii International Conference on System Sciences (HICSS'07). IEEE; 2007:179c.

39. Nonnecke B, Preece J. Why lurkers lurk. In: AMCIS 2001 proceedings; 2001:294.

40. Schneider A, Von Krogh G, Jäger P. "What's coming next?" Epistemic curiosity and lurking behavior in online communities. Comput Human Behav. 2013;29(1):293-303. doi:10.1016/j.chb.20 12.09.008

41. Bonacich P, Schneider S. Social Dilemmas. In: Theoretical Issues and Research Findings; 1992.

42. Liebrand W, Messick D, Wilke H. Social Dilemmas: Theoretical Issues and Research Findings. Garland Science; 2015.
43. Nahapiet J, Ghoshal S. Social capital, intellectual capital, and the organizational advantage. Acad Manag Rev. 1998;23(2):242-266. doi:10.5465/amr.1998.533225

44. Fiedler M, Sarstedt M. Influence of community design on user behaviors in online communities. J Bus Res. 2014;67(11):22 58-2268. doi:10.1016/j.jbusres.2014.06.014

45. Wright KB. Communication in health-related online social support groups/communities: a review of research on predictors of participation, applications of social support theory, and health outcomes. Rev Commun Res. 2016;4:65-87. doi:10.12840/issn.2255-4165.2016.04. 01.010

46. Coulson NS, Buchanan H, Aubeeluck A. Social support in cyberspace: a content analysis of communication within a Huntington's disease online support group. Patient Educ Couns. 2007;68 (2):173-178. doi:10.1016/j.pec.2007.06.002

47. Wasko MM, Faraj S. Why should I share? Examining social capital and knowledge contribution in electronic networks of practice. MIS Q. 2005;29(1):35-57. doi:10.2307/25148667

48. Casaló LV, Flavián C, Guinalíu M. New members' integration: key factor of success in online travel communities. J Bus Res. 2013;66 (6):706-710. doi:10.1016/j.jbusres.2011.09.007

49. Du Y. Modeling the behavior of lurkers in online communities using intentional agents. In: 2006 International Conference on Computational Inteligence for Modelling Control and Automation and International Conference on Intelligent Agents Web Technologies and International Commerce (CIMCA'06). IEEE; 2006:60.

50. Nonnecke B, Preece J. Lurker demographics: counting the silent. In: Proceedings of the SIGCHI conference on Human factors in computing systems; 2000:73-80.

51. Kordzadeh N, Warren J. Communicating personal health information in virtual health communities: an integration of privacy calculus model and affective commitment. J Assoc Inf Syst. 2017;18(1):1. doi:10.17705/1jais.00446

52. Mathwick C, Wiertz C, De RK. Social capital production in a virtual P3 community. J Consum Res. 2008;34(6):832-849. doi:10.1086/ 523291

53. Sadeque F, Pedersen T, Solorio T, et al. Why do they leave: modeling participation in online depression forums. In: Proceedings of The Fourth International Workshop on Natural Language Processing for Social Media; 2016:14-19.

54. Lu Y, Pan T, Deng S. What drives patients affected by depression to share in online depression communities? A social capital perspective. Healthcare. 2019;7(4):133. doi:10.3390/healthcare7040133

55. Phillips MR, Zhang J, Shi Q, et al. Prevalence, treatment, and associated disability of mental disorders in four provinces in China during 2001 05: an epidemiological survey. Lancet. 2009;373 (9680):2041-2053. doi:10.1016/S0140-6736(09)60660-7

56. Xiang YT, Xin Y, Sartorius N, et al. Mental health in China: challenges and progress. Lancet. 2012;380(9855):1715. doi:10.1016/ S0140-6736(11)60893-3

57. The report on depression in China in 2019 [homepage on the Internet]. Depression Institute; 2019. Available from: https://zhuan lan.zhihu.com/p/98203512. Accessed December 19, 2011.

58. Benton A, Coppersmith G, Dredze M. Ethical research protocols for social media health research. In: Proceedings of the First ACL Workshop on Ethics in Natural Language Processing; 2017:94-102.

59. Alexander SC, Peterson JL, Hollingshead AB. Help is at your keyboard: support groups on the Internet. In: Group Communication in Context: Studies of Bona Fide Groups. Vol. 2; 2003:309-334.

60. Muncer S, Burrows R, Pleace N, et al. Births, deaths, sex and marriage but very few presents? A case study of social support in cyberspace. Crit Public Health. 2000;10(1):1-18. doi:10.1080/7136 58221

61. Devlin J, Chang MW, Lee K, Toutanova K. Bert: pre-training of deep bidirectional transformers for language understanding. arXiv preprint arXiv:1810.04805; 2018. 
62. Madabushi HT, Kochkina E, Castelle M. Cost-sensitive BERT for generalisable sentence classification with imbalanced data. arXiv preprint arXiv:2003.11563; 2020.

63. Van Asch V. Macro-and micro-averaged evaluation measures. Belgium: CLiPS; 2013:49.

64. Malika C, Ghazzali N, Boiteau V, Niknafs A. NbClust: an R package for determining the relevant number of clusters in a data Set. J Stat Softw. 2014;61:1-36.

65. Lakhani KR, Von Hippel E. How open source software works:"free" user-to-user assistance. Research Policy. 2000;32(6):923-943.

66. Thompson RJ, Mata J, Jaeggi SM, et al. The everyday emotional experience of adults with major depressive disorder: examining emotional instability, inertia, and reactivity. J Abnorm Psychol. 2012;121 (4):819. doi:10.1037/a0027978

67. Cavazos-Rehg PA, Krauss MJ, Sowles S, et al. A content analysis of depression-related tweets. Comput Human Behav. 2016;54:351-357. doi:10.1016/j.chb.2015.08.023

68. De Choudhury M, Counts S, Horvitz E. Social media as a measurement tool of depression in populations. In: Proceedings of the 5th annual ACM web science conference; 2013:47-56.

69. Settanni M, Marengo D. Sharing feelings online: studying emotional well-being via automated text analysis of Facebook posts. Front Psychol. 2015;6:1045. doi:10.3389/fpsyg.2015.01045

70. Guo L, Zhou X, Lu T, et al. SunForum: understanding depression in a Chinese online community. In: The 19th ACM Conference. ACM; 2016.

71. Chung JE. Social networking in online support groups for health: how online social networking benefits patients. J Health Commun. 2014;19(6):639-659. doi:10.1080/10810730.2012.757396

72. Yang X, Li G, Huang SS. Perceived online community support, member relations, and commitment: differences between posters and lurkers. Inf Manag. 2017;54(2):154-165. doi:10.1016/j.im.2016.05.003
73. Ye HJ, Feng Y, Choi BC. Understanding knowledge contribution in online knowledge communities: a model of community support and forum leader support. Electron Commer Res Appl. 2015;14(1):34-45. doi:10.1016/j.elerap.2014.11.002

74. Zhang Y, Zhang M, Luo N, et al. Understanding the formation mechanism of high-quality knowledge in social question and answer communities: a knowledge co-creation perspective. Int J Inf Manag. 2019;48:72-84. doi:10.1016/j.ijinfomgt.2019.01.022

75. Chang HH, Chuang SS. Social capital and individual motivations on knowledge sharing: participant involvement as a moderator. Inf Manag. 2011;48(1):9-18. doi:10.1016/j.im.2010.11.001

76. Sun Y, Fang Y, Lim KH. Understanding sustained participation in transactional virtual communities. Decis Support Syst. 2012;53 (1):12-22. doi:10.1016/j.dss.2011.10.006

77. Ryan RM, Deci EL. Intrinsic and extrinsic motivations: classic definitions and new directions. Contemp Educ Psychol. 2000;25 (1):54-67. doi:10.1006/ceps.1999.1020

78. Sun N, Rau PPL, Ma L. Understanding lurkers in online communities: a literature review. Comput Human Behav. 2014;38:110-117. doi:10.1016/j.chb.2014.05.022

79. Lu X, White H. Robustness checks and robustness tests in applied economics. J Econom. 2014;178:194-206. doi:10.1016/j. jeconom.2013.08.016

80. Van Mierlo T. The $1 \%$ rule in four digital health social networks: an observational study. J Med Internet Res. 2014;16(2):33. doi:10.2196/ jmir.2966

81. Guo X, Guo S, Vogel D, Li Y. Online healthcare community interaction dynamics. J Manag Sci Eng. 2016;1(1):58-74. doi:10.3724/SP. J.1383.101004

82. Kashdan TB, Rottenberg J. Psychological flexibility as a fundamental aspect of health. Clin Psychol Rev. 2010;30(7):865-878. doi:10.1016/ j.cpr.2010.03.001
Psychology Research and Behavior Management

\section{Publish your work in this journal}

Psychology Research and Behavior Management is an international, peer-reviewed, open access journal focusing on the science of psychology and its application in behavior management to develop improved outcomes in the clinical, educational, sports and business arenas. Specific topics covered in the journal include: Neuroscience, memory and decision making; Behavior modification and management; Clinical

\section{Dovepress}

applications; Business and sports performance management; Social and developmental studies; Animal studies. The manuscript management system is completely online and includes a very quick and fair peer-review system, which is all easy to use. Visit http://www. dovepress.com/testimonials.php to read real quotes from published authors. 